\title{
BMI open Neonatal complications in public and private patients: a retrospective cohort study
}

\author{
Kristjana Einarsdóttir, ${ }^{1}$ Sarah Stock, ${ }^{2}$ Fatima Haggar, ${ }^{3}$ Geoffrey Hammond, ${ }^{1}$ \\ Amanda T Langridge, ${ }^{1}$ David B Preen, ${ }^{3}$ Nick De Klerk, ${ }^{1}$ Helen Leonard, ${ }^{1}$ \\ Fiona J Stanley ${ }^{1}$
}

To cite: Einarsdóttir K, Stock S, Haggar F, et al. Neonatal complications in public and private patients: a retrospective cohort study. BMJ Open 2013;3:e002786. doi:10.1136/bmjopen-2013002786

- Prepublication history for this paper are available online. To view these files please visit the journal online (http://dx.doi.org/10.1136/ bmjopen-2013-002786).

Received 25 February 2013 Revised 11 April 2013 Accepted 25 April 2013

This final article is available for use under the terms of the Creative Commons Attribution Non-Commercial 2.0 Licence; see http://bmjopen.bmj.com

${ }^{1}$ Telethon Institute for Child Health Research, Centre for Child Health Research, University of Western Australia, Perth, Western Australia, Australia

${ }^{2}$ School of Women's and Infant's Health, University of Western Australia, King Edward Memorial Hospital, Perth, Western Australia, Australia

${ }^{3}$ Centre for Health Services Research, School of Population Health, The University of Western Australia, Perth, Western Australia, Australia

\section{Correspondence to} Dr Kristjana Einarsdóttir; keinarsdottir@ichr.uwa.edu. $\mathrm{au}$

\section{ABSTRACT}

Objective: To use propensity score methods to create similar groups of women delivering in public and private hospitals and determine any differences in mode of delivery and neonatal outcomes between the matched groups.

Design: Population-based, retrospective cohort study. Setting: Public and private hospitals in Western Australia. Participants: Included were 93802 public and 66479 private singleton, term deliveries during 1998-2008, from which 32757 public patients were matched with 32757 private patients on the propensity score of maternal characteristics.

Main outcome measures: Neonatal outcomes were compared in the propensity score-matched cohorts using conditional logistic regression, adjusted for antenatal risk factors and mode of delivery. Outcomes included Apgar score $<7$ at $5 \mathrm{~min}$, neonatal resuscitation (endotracheal intubation or external cardiac massage) and admission to a neonatal special care unit.

Results: No significant differences in maternal characteristics were found between the propensity scorematched groups. Private patients were more likely than their matched public counterparts to undergo prelabour caesarean section $(25.2 \%$ vs $18 \%, p<0.0001)$. Public patients had lower rates of neonatal unit admission (AOR $0.67,95 \% \mathrm{Cl} 0.62$ to 0.73 ) and neonatal resuscitation (AOR $0.73,95 \% \mathrm{Cl} 0.56$ to 0.95 ), but higher rates of low Apgar scores at 5 min (AOR 1.31, 95\% Cl 1.06 to 1.63) despite adjustment for antenatal factors. Additional adjustment for mode of delivery reduced the resuscitation risk (AOR $0.86,95 \% \mathrm{Cl} 0.63$ to 1.18) but did not significantly alter the other estimates.

Conclusions: Propensity score methods can be used to generate comparable groups of public and private patients. Despite the rates of low Apgar scores being higher in public patients, the rates of special care admission were lower. Whether these findings stem from differences in paediatric services or clinical factors is yet to be determined.

\section{INTRODUCTION}

Studies from Australia and the USA have indicated that privately insured mothers have

\section{ARTICLE SUMMARY}

Article focus

- Obstetric interventions are higher for women giving birth in private hospitals compared to public hospitals despite their social and health advantages.

- Differences in characteristics between public and private patients make it challenging to determine whether the higher rate of obstetric interventions in the private sector increases adverse neonatal outcomes.

- The study aim was to use propensity score methods to create similar groups of women delivering in public and private hospitals and determine any neonatal outcomes and mode of delivery differences between the matched groups.

Key messages

- Maternal characteristics were similar between the public and private groups after propensity score matching, yet private patients were still more likely to undergo prelabour caesarean sections.

- After matching and adjusting for antenatal risk factors, the rates of low Apgar scores were slightly higher in public patients, but the rates of admission to a neonatal unit were lower.

- These differences could not be accounted for by the higher rate of caesarean deliveries in private hospitals.

Strengths and limitations of this study

- Propensity score matching methods have been found to account well for measured confounding.

- Using this method enabled us to account for differences in maternal characteristics between public and private patients where information was available.

- Nevertheless, as some information was unavailable, some residual confounding may have impacted our results.

better maternal and infant health outcomes than women who deliver as public patients in public hospitals. ${ }^{1}{ }^{2}$ However, mothers giving birth as private patients are less 
socioeconomically deprived and generally healthier than women who are public patients. ${ }^{3-5}$ It would therefore be anticipated that they would have better pregnancy outcomes. Yet, obstetric intervention rates have risen more rapidly in the private than the public sector during the last couple of decades. ${ }^{6}$ Now, women who hold private insurance and who do not receive midwife-led care in Australia, the USA and other parts of the world have higher rates of obstetric interventions, such as prelabour caesarean section, induction of labour and operative vaginal delivery, than other women. ${ }^{1}{ }^{78}$ Such high rates of obstetric interventions may be associated with increased morbidity for both the mother and the baby. ${ }^{9-11}$

The maternal characteristics of private patients and the model of their obstetric care may have opposing influences on neonatal outcomes, but to date exploring the relative effects of these has been challenging. This may be because a direct comparison of private and public patients is difficult due to the large differences between the groups. In randomised controlled trials, the random allocation of patients into comparison groups guarantees an equal distribution of confounding factors between the groups. In observational studies such as this one, randomisation of subjects into groups is not feasible and because the number of confounding variables is high between public and private patients, traditional methods of matching or covariate adjustment may become problematic. The propensity score method is a way of circumventing these problems ${ }^{12}{ }^{13}$ and has recently begun to be used within obstetrics to reduce or eliminate fundamental differences between comparison groups. ${ }^{14} 15$

In this study, we used propensity score methods in an attempt to create similar groups of public and private patients for comparison of neonatal outcomes and mode of delivery. First, the propensity of being a private patient based on the available maternal characteristics was estimated. Then the estimated propensity scores were used to individually match public with private patients. Finally, we assessed the differences in adverse neonatal outcomes between the matched groups using conditional logistic regression. We first hypothesised that rates of obstetric interventions are different between private and public patients even after matching on maternal characteristics; and second, that increased interventions may have a negative effect on neonatal outcomes.

\section{METHODS}

\section{Data sources}

The Data Linkage Branch at the Western Australian (WA) Department of Health provided whole-population, linked administrative health data from the WA Midwives Notification System (MNS), the WA Hospital Morbidity Data Collection (HMDC) and the WA Birth Defects Registry for the period 1 January 1998 to 31 December 2008 for this study. The midwives' data included pregnancy and delivery details for all infants live or stillborn in WA during 1998-2008 at least at 20 weeks' gestation or with a birth weight of at least $400 \mathrm{~g}$. For the study population included in this study, we restricted the data to singleton, term births (weeks 37-41), resulting in liveborn infants without birth defects and delivered in either private or public hospitals (excluding tertiary hospitals).

MNS included information on the Index of Relative Socioeconomic (SE) Disadvantage (IRSD) and Accessibility/Remoteness Index of Australia (ARIA+). The IRSD and ARIA values were based on the 2001 and 2006 Censuses and were assigned to each birth admission based on maternal area of residence at the time of birth. HMDC provided information on funding source and hospital type at the time of delivery, with private patients being defined as those who were funded by private health insurance or who were self-funded. We only included mothers delivering as public patients in public hospitals and mothers delivering as private patients in private hospitals in this study.

The use of deidentified, administrative health data for this study without patient consent was approved by the Human Research Ethics Committee of the WA Department of Health. This study was performed in accordance with the Declaration of Helsinki.

\section{Statistical analysis}

The propensity scores were generated by a logistic regression model and represented the probability of delivering as a private patient in a private hospital given the maternal characteristics, squared terms and interactions included as covariates in the propensity model. ${ }^{13}$ The following maternal characteristics were significant in the forward selection model $(\mathrm{p}<0.05)$ and were included in the propensity model in addition to 32 interaction terms and one square term for age: maternal age (continuous), parity (ordinal; 14 levels), marital status (categorical; married/single), ethnicity (categorical; eight levels), smoking during pregnancy (categorical; yes/no), SE disadvantage (categorical; five levels), residential remoteness (categorical; five levels), pre-existing genital herpes, diabetes mellitus and asthma (categorical; yes/no), previous caesarean (categorical; yes/no) and fertility treatment (categorical; yes/no).

We conducted 1:1 matching without replacement to match each private patient in a private hospital with each public patient in a public hospital within $0.25 \mathrm{SD}$ of the logit of the propensity score of the identified private patient. ${ }^{12}$ The balance of the covariates before and after matching was assessed using a standardised difference since, unlike significance testing, it is not confounded by sample size. ${ }^{12}$ A standardised difference greater than $10 \%$ was used to indicate a meaningful difference between public and private patients. ${ }^{14}$ We used conditional logistic regression of the matched sets to estimated ORs and 95\% CIs for the risk of adverse infant outcomes for public patients in public hospitals compared with private patients in private hospitals. Infant outcomes included Apgar scores $<7$ at 5 min, neonatal resuscitation (endotracheal intubation or external 
cardiac massage) and neonatal admission to a special care nursery. These outcome measures were selected since they are easy to measure and do not only reflect the neonatal condition, but also the practice differences between hospitals. ${ }^{16}$ The models were adjusted for antenatal risk factors including threatened miscarriage, placenta praevia and prelabour rupture of membranes as well as the mode of delivery. All analyses were performed using the statistical software SAS V.9.3 (SAS Institute Inc, Cary, North Carolina, USA).

\section{RESULTS}

Propensity score matching

Of the total 160281 deliveries included in this study, $93802(58.5 \%)$ were by public patients in public hospitals and $66479(41.5 \%)$ were by private patients in private hospitals. Table 1 presents the baseline maternal characteristics of the two groups before matching. All characteristics were statistically significantly different $(p<0.0001)$ and all except parity, genital herpes, diabetes mellitus and asthma were meaningfully different based on the standardised difference $( \pm 10 \%)$.

Figure 1 displays the distribution of the propensity scores for the public and private deliveries. We were able to match 32757 public deliveries with private deliveries and from figure 2 it is evident that after matching, the propensity scores for the public and private births revealed a high degree of overlap and similarity in shape. Furthermore, all baseline characteristics were well balanced after matching (table 2). Although maternal age and pre-existing asthma were statistically significantly different between the two matched groups, the differences were small with a highest standardised difference

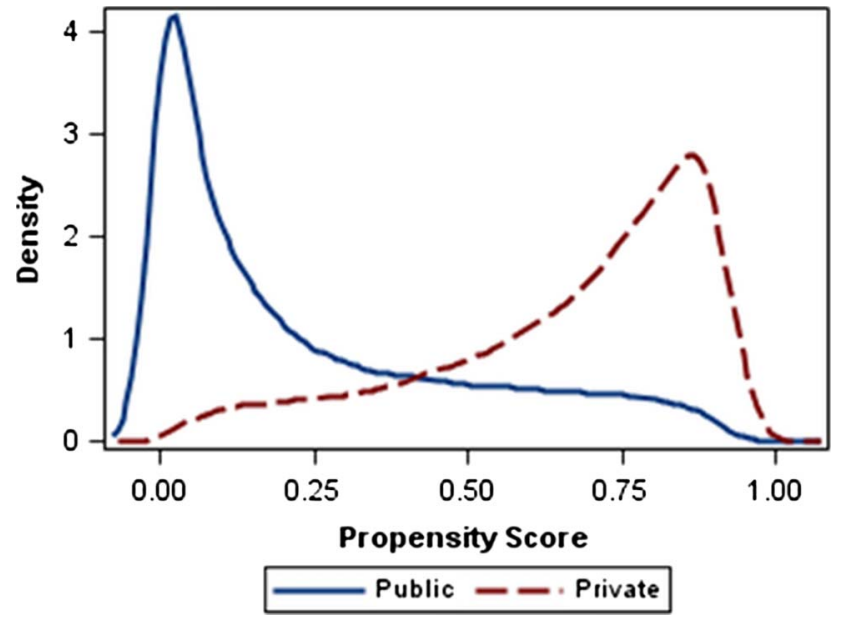

Figure 1 Distribution of the propensity scores for public and private patients before matching (160 281WA deliveries).

of only 2.6 (table 2). The differences (mean age 0.1 year, and proportion of women with asthma $0.5 \%$ higher in the private group) are unlikely to be of clinical significance.

\section{Neonatal outcomes}

Following matching by propensity score and ensuring comparability in the baseline characteristics of the groups, we assessed whether there were any differences in antenatal complications between the groups (table 3 ). No significant differences were observed between matched public and private patients with regard to threatened preterm labour, urinary tract infection, preeclampsia, placental abruption or gestational diabetes. However, private patients were more likely to experience

Table 1 Maternal characteristics used for determination of the propensity score for $160281^{*}$ WA unmatched public and private births

\begin{tabular}{|c|c|c|c|c|}
\hline & $\begin{array}{l}\text { Public patients in public } \\
\text { hospitals }(n=93802) \\
\text { Mean }( \pm S D)\end{array}$ & $\begin{array}{l}\text { Private patients in } \\
\text { private hospitals } \\
\text { ( } n=66479) \\
\text { Mean }( \pm S D)\end{array}$ & p Valuet & $\begin{array}{l}\text { Standardised } \\
\text { difference (\%) }\end{array}$ \\
\hline Maternal age (years) & $\begin{array}{c}27.6(5.7) \\
\text { n (\%) }\end{array}$ & $\begin{array}{c}31.8(4.4) \\
n(\%)\end{array}$ & $<0.0001$ & 16.55 \\
\hline Parity (2nd+ child) & $52119(55.6)$ & $34405(51.8)$ & $<0.0001$ & -7.65 \\
\hline Single/divorced/widowed & $10031(10.7)$ & $1726(2.6)$ & $<0.0001$ & -32.92 \\
\hline Indigenous & $8273(8.8)$ & $144(0.2)$ & $<0.0001$ & -42.31 \\
\hline Smoking during pregnancy & $26642(28.4)$ & $3292(5.0)$ & $<0.0001$ & -66.27 \\
\hline SE disadvantage & $47808(51.0)$ & $10135(15.3)$ & $<0.0001$ & -82.04 \\
\hline Regional/remote residence & 39568 (42.2) & $5786(8.7)$ & $<0.0001$ & -83.27 \\
\hline Genital herpes & $1401(1.5)$ & $1692(2.6)$ & $<0.0001$ & 7.54 \\
\hline Diabetes mellitus & $135(0.1)$ & $245(0.4)$ & $<0.0001$ & 4.56 \\
\hline Asthma & $10090(10.8)$ & $6611(9.9)$ & $<0.0001$ & -2.69 \\
\hline Previous caesarean & $9833(10.5)$ & 12558 (18.9) & $<0.0001$ & 23.93 \\
\hline Fertility treatment & $843(0.9)$ & 2156 (3.2) & $<0.0001$ & 16.49 \\
\hline
\end{tabular}




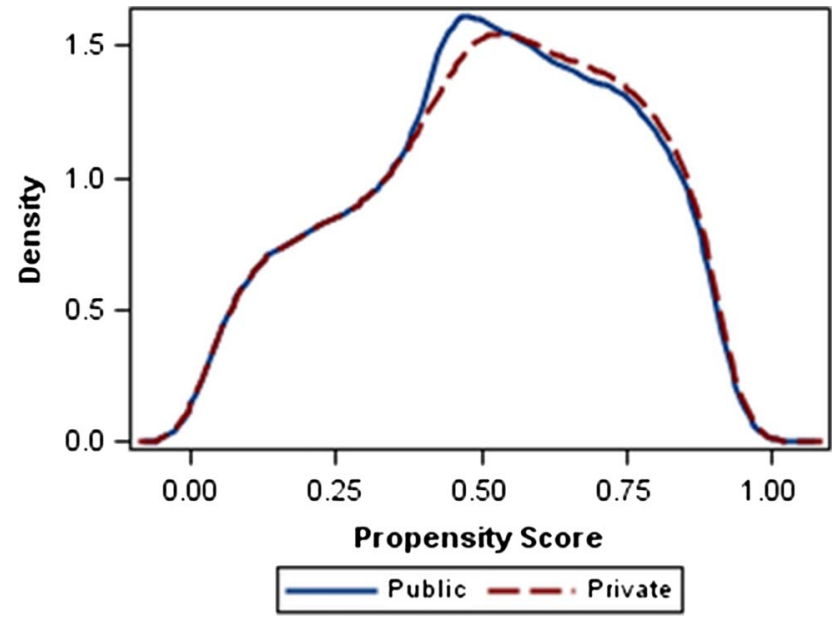

Figure 2 Distribution of the propensity scores for public and private patients after matching (65 514WA deliveries).

threatened miscarriage $(6.7 \%$ vs $4.6 \% ; \mathrm{p}<0.001)$ and placenta praevia $(0.7 \%$ vs $0.3 \%$; $\mathrm{p}<0.0001)$, but were less likely to experience prelabour rupture of membranes $(1.7 \%$ vs $3.9 \% \mathrm{p}<0.0001)$.

We then assessed the differences in labour and delivery management between the matched public and private groups (table 3). Private patients were delivered at earlier gestations than public patients, with $64.3 \%$ of private patients delivering before 40 weeks' gestation compared to $47.2 \%$ of public patients $(\mathrm{p}<0.0001)$, and infants had a slightly lower mean birth weight (3443.9 g vs $3498.8 \mathrm{~g}, \mathrm{p}<0.0001)$. Private patients were also more likely to have induction of labour or prelabour caesarean section than public patients, with only $38.3 \%$ of private patients labouring spontaneously, compared to $55.2 \%$ of public patients. Private patients were more likely to have epidural anaesthesia during labour, and mode of delivery was also different, with private patients having higher rates of assisted vaginal delivery $(18.2 \%$ vs $12.3 \% ; \mathrm{p}<0.0001)$ and prelabour caesarean section ( $25.5 \%$ vs $18 \%)$.

When assessing the risk of neonatal complications for mothers delivering as public patients compared with those delivering as private patients, we first adjusted only for the antenatal complications that were significantly different between the matched groups. These antenatal complications were included in a multivariate analysis (table 4) and despite the adjustment, the results indicated that delivering as a public patient was associated with increased risk of low Apgar scores (AOR 1.31, 95\% CI 1.06 to 1.63 ), but reduced risk of neonatal resuscitation (AOR 0.73, 95\% CI 0.56 to 0.95 ) and admission to a neonatal unit (AOR $0.67,95 \%$ CI 0.62 to 0.73 ). The absolute differences were however minimal for low Apgar scores and neonatal resuscitation as only $0.6 \%$ of infants born in public hospitals had low Apgar scores compared to $0.5 \%$ in private hospitals and only $0.3 \%$ were resuscitated in public hospitals versus $0.4 \%$ in private hospitals.

Next, we explored whether delivery management accounted for the observed associations. Table 4 shows that adjusting for mode of delivery reduced the risk of infant resuscitation (OR $0.86,95 \%$ CI 0.63 to 1.18 ) to the point where it was no longer statistically significant, but the additional adjustment did not significantly alter the other estimates.

\section{DISCUSSION}

Our findings suggest that propensity score methods can be successfully used to create comparable groups of mothers delivering in public and private hospitals. However, despite including in our analysis only those

Table 2 Maternal characteristics of the $65514^{*}$ WA public and private births that were individually matched on the propensity score

\begin{tabular}{|c|c|c|c|c|}
\hline & $\begin{array}{l}\text { Public patients in public } \\
\text { hospitals }(n=32757) \\
\text { Mean }( \pm S D)\end{array}$ & $\begin{array}{l}\text { Private patients in private } \\
\text { hospitals }(n=32757) \\
\text { Mean }( \pm S D)\end{array}$ & p Valuet & $\begin{array}{l}\text { Standardised } \\
\text { difference (\%) }\end{array}$ \\
\hline Maternal age (years) & $\begin{array}{c}30.3(4.7) \\
\text { n (\%) }\end{array}$ & $\begin{array}{c}30.4(4.7) \\
\mathrm{n}(\%)\end{array}$ & 0.0009 & 2.60 \\
\hline Parity (2nd+ child) & $16642(50.8)$ & $16713(51.0)$ & 0.58 & 0.44 \\
\hline Single/divorced/widowed & $1255(3.8)$ & $1247(3.8)$ & 0.87 & -0.10 \\
\hline Indigenous & $101(0.3)$ & $112(0.3)$ & 0.45 & 0.53 \\
\hline Smoking during pregnancy & $2937(9.0)$ & 2925 (8.9) & 0.87 & -0.14 \\
\hline SE disadvantage & $8936(27.3)$ & $8762(26.8)$ & 0.13 & -1.19 \\
\hline Regional/remote residence & $5403(16.5)$ & 5369 (16.4) & 0.72 & -0.27 \\
\hline Genital herpes & $597(1.8)$ & $646(2.0)$ & 0.16 & 1.10 \\
\hline Diabetes mellitus & $49(0.2)$ & $44(0.1)$ & 0.60 & -0.53 \\
\hline Asthma & $2962(9.0)$ & $3121(9.5)$ & 0.03 & 1.69 \\
\hline Previous caesarean & 4525 (13.8) & $4575(14.0)$ & 0.57 & 0.46 \\
\hline Fertility treatment & $533(1.6)$ & $586(1.8)$ & 0.11 & 1.23 \\
\hline
\end{tabular}

${ }^{*}$ Restricted to singleton, term births in non-tertiary hospitals, resulting in live-born infants without birth defects. $\mathrm{tt}$ Test for means and $\chi^{2}$ test of independence for proportions.

$\mathrm{SE}$, socioeconomic. 
Table 3 Antenatal and delivery characteristics of the $65514^{*}$ WA public and private births that were individually matched on the propensity score of maternal characteristics

\begin{tabular}{|c|c|c|c|c|}
\hline & $\begin{array}{l}\text { Public patients in public } \\
\text { hospitals }(n=32757)\end{array}$ & $\begin{array}{l}\text { Private patients in private } \\
\text { hospitals }(n=32757)\end{array}$ & $\begin{array}{l}\text { Degrees of } \\
\text { freedom }\end{array}$ & p Valuet \\
\hline Antenatal risk factors & $\mathrm{N}(\%)$ & n (\%) & & \\
\hline $\begin{array}{l}\text { Threatened miscarriage } \\
(<20 \text { weeks) }\end{array}$ & $1507(4.6)$ & $2192(6.7)$ & 1 & $<0.0001$ \\
\hline $\begin{array}{l}\text { Threatened preterm labour } \\
\text { (<37 weeks) }\end{array}$ & $349(1.1)$ & $388(1.2)$ & 1 & 0.15 \\
\hline Urinary tract infection & $921(2.8)$ & 869 (2.7) & 1 & 0.21 \\
\hline Pre-eclampsia & $1227(3.8)$ & $1135(3.5)$ & 1 & 0.05 \\
\hline Placenta praevia & $110(0.3)$ & $220(0.7)$ & 1 & $<0.0001$ \\
\hline Placental abruption & $79(0.2)$ & $64(0.2)$ & 1 & 0.21 \\
\hline Prelabour rupture of membranes & $1263(3.9)$ & $541(1.7)$ & 1 & $<0.0001$ \\
\hline Gestational diabetes & $1237(3.8)$ & $1166(3.6)$ & 1 & 0.14 \\
\hline \multicolumn{5}{|l|}{ Gestation (weeks) } \\
\hline 37 & $1650(5.0)$ & $2571(7.9)$ & & \\
\hline 38 & 6659 (20.3) & $12226(31.2)$ & & \\
\hline 39 & 7183 (21.9) & 8255 (25.2) & & \\
\hline 40 & 12507 (38.2) & 9497 (29.0) & & \\
\hline 41 & 4758 (14.5) & $2208(6.7)$ & 4 & $<0.0001$ \\
\hline \multicolumn{5}{|l|}{ Onset of labour } \\
\hline Spontaneous & $18078(55.2)$ & 12549 (38.3) & & \\
\hline Induction & 8800 (26.9) & $11967(36.5)$ & & \\
\hline Caesarean & $5879(18.0)$ & 8241 (25.2) & 2 & $<0.0001$ \\
\hline \multicolumn{5}{|l|}{ Mode of delivery } \\
\hline Unassisted vaginal & $19351(59.1)$ & $14822(45.3)$ & & \\
\hline Assisted vaginal & 4017 (12.3) & 5973 (18.2) & & \\
\hline Caesarean with labour & $3510(10.7)$ & $3721(11.4)$ & & \\
\hline Caesarean without labour & $5879(18.0)$ & $8,241(25.2)$ & 3 & $<0.0001$ \\
\hline \multirow[t]{2}{*}{ Epidural during labour $\ddagger$} & 9189 (34.2) & $14708(60.0)$ & 1 & $<0.0001$ \\
\hline & Mean ( \pm SD) & Mean ( $(\mathrm{SD})$ & & \\
\hline Infant weight (g) & $3498.8(457.4)$ & $3443.9(439.4)$ & & $<0.0001$ \\
\hline
\end{tabular}

public and private patients who had similar maternal characteristics and antenatal factors and thus comparing 'like-with-like', obstetric interventions continued to be performed at a much higher rate in the private sector. Also, delivering as a public patient was associated with an increased risk of low Apgar scores at $5 \mathrm{~min}$, but reduced risk of admission to a neonatal unit.

One of the strengths of this study is the whole of the population design. This study draws on the wealth of statutory birth and hospital inpatient information routinely collected by the WA Department of Health. The main limitations of this study relate to the possibility of unmeasured confounding. Propensity score matching methods have been found to account well for measured confounding $^{12}$ and using propensity score matching enabled us to eliminate differences between public and private patients for the maternal characteristics where information was available. Nevertheless, as we did not

Table 4 Risk of adverse neonatal outcomes after birth for $32757^{\star}$ public patients compared with $32757^{\star}$ private patients who were individually matched on the propensity score of maternal characteristics

\begin{tabular}{|c|c|c|c|}
\hline & $\begin{array}{l}\text { Apgar score at } 5 \mathrm{~min}<7 \\
\mathrm{n}(\%)\end{array}$ & $\begin{array}{l}\text { Resuscitation † } \\
\text { OR }(95 \% \mathrm{Cl})\end{array}$ & $\begin{array}{l}\text { Admission to special care } \\
\text { OR }(95 \% \mathrm{Cl})\end{array}$ \\
\hline Private patients & $152(0.5)$ & $142(0.4)$ & $1507(4.6)$ \\
\hline Public patients & $206(0.6)$ & $101(0.3)$ & $1029(3.1)$ \\
\hline Unadjusted model & $1.36(1.10$ to 1.68$)$ & 0.71 (0.55 to 0.92$)$ & $0.67(0.62$ to 0.73$)$ \\
\hline Adjusted for antenatal factors & 1.31 (1.06 to 1.63$)$ & 0.73 (0.56 to 0.95$)$ & 0.67 (0.62 to 0.73$)$ \\
\hline Also adjusted for mode of delivery & $1.31(1.04$ to 1.66$)$ & $0.86(0.63$ to 1.18$)$ & $0.73(0.67$ to 0.80$)$ \\
\hline
\end{tabular}

${ }^{*}$ Restricted to singleton, term births in non-tertiary hospitals, resulting in live-born infants without birth defects.

†Endotracheal intubation or external cardiac massage. 
have information on body mass index (BMI) before pregnancy, gestational weight gain or maternal diet to name a few, some residual confounding may have distorted our results. However, as, for example, SE disadvantage has been shown to be associated with mothers' weight gain during pregnancy, ${ }^{17}$ we believe that residual confounding was minimised through the covariates we were able to include in our propensity score model.

Birth outcomes between public and private patients have previously been studied in Australia. ${ }^{2}$ Robson et al included Australian deliveries, restricted to singleton, term births, and after adjusting for maternal age, ethnicity, smoking status, diabetes, hypertension, residential remoteness and mode of delivery, the authors found higher rates of all adverse outcomes for public births compared with private births. ${ }^{2}$ Coory et al ${ }^{18}$ replicated some of the results from Robson et al using Queensland data, both using the same variables for adjustment as well as after adjusting for additional maternal characteristics and antenatal risk factors. When we performed exactly the same analysis as Robson et al using the same study cohort, we found that public patients in public hospitals had an increased risk of low Apgar score at $5 \mathrm{~min}$ (OR 1.90, 95\% CI 1.76 to 2.06) and neonatal resuscitation (OR 2.66, 95\% CI 2.46 to 2.86), compared to private patients in private hospitals. Our results were almost identical to those of Robson et al (low Apgar scores: OR=1.75; neonatal resuscitation: OR 2.37). ${ }^{2}$ This indicates that even though the propensity score analysis in the current study may not have eliminated all differences between public and private patients, it seems to have significantly minimised those differences.

Our results supported previous findings showing that privately insured women are more likely to have obstetric interventions than other women, even after taking into account maternal characteristics and pregnancy risk factors. ${ }^{7}$ It is very likely that there are many reasons for this difference in intervention rates between the private and public sectors, including fear of litigation, ${ }^{19}$ maternal request, ${ }^{20}$ physician convenience, ${ }^{21} 22$ previous caesarean section ${ }^{23}$ and increase in the numbers of women with private health insurance in Australia. ${ }^{24}$ However, elective caesarean deliveries have been found to increase the risk of respiratory morbidity in infants born at full-term, compared with vaginal deliveries or emergency caesarean deliveries. ${ }^{10}$ Our results reflected this since public patients were observed to have decreased risk of neonatal resuscitation compared with private patients, which was largely accounted for by the higher rate of prelabour caesarean deliveries in the private sector. Nevertheless, some of the association could be explained by differences in availability of medical staff at private and public hospitals. Neonatal intubation is commonly used by skilled senior paediatricians to assist in the clearance of airways with meconium and paediatricians are more likely to be on hand to perform this task during care of the newborn in private hospitals instead of, for example, resident medical officers or other junior staff at public hospitals.

Apgar scores at 5 min have been reported to be better in healthy infants born by elective caesarean deliveries than in other infants ${ }^{25}$ and this appeared to be reflected in our results since public patients had a higher risk of a low Apgar score than private patients. The fact, however, that accounting for the mode of delivery in the analysis did not change the results renders this argument unlikely. Our results are thus more likely to reflect residual differences in maternal and pregnancy characteristics between the matched groups or perhaps practice differences between public and private hospitals. These differences are however likely to be minimal and clinically irrelevant as the absolute difference in risk was very small with only a $0.1 \%$ difference between public and private hospitals. Furthermore, Apgar score assignment is subject to variation; for example, under difficult conditions when the situation in the delivery room may become tense, the assignment of Apgar scores may be incomplete or delayed. ${ }^{26}$

Differences in delivery management also did not seem to account for the fact that infants of public patients were less likely to be admitted to neonatal special care nursery than infants of private patients in our study. Previous research suggests that clinical evaluation remains inexact when discriminating between infants needing special care and those who do not. ${ }^{27}$ Large variation has been found to exist between special care nurseries in the initial management of infants with respiratory distress and in the thresholds to transfer to a neonatal intensive care unit. ${ }^{16}$ Since infants become separate fee paying patients from the mother once they are admitted to a special care unit in Australian hospitals, an admission can create additional funds for the hospital if the mother is a private patient. ${ }^{28}$ However, if the mother is a public patient, the costs for admission of a baby to the unit are borne by the hospital. As such, there may be an incentive for private hospitals to encourage paediatricians to admit borderline infants for observation, and thus some may be offered admission to a special care nursery unnecessarily. ${ }^{29}$ Furthermore, fee paying mothers have greater expectations for their own hospital care and the care of their infant ${ }^{7}$ as they are generally well educated, confident and with high selfesteem and have been found to be at higher risk of obstetric interventions. ${ }^{30}$ However, the possibility of unnecessary admissions to special care nurseries, as alluded to above, may prove to be a double-edged sword as newborn hospitalisation can compromise breastfeeding and early maternal attachment. ${ }^{31} 32$ In fact, previous research has suggested that infants with mild complications may benefit from remaining with the mother in the postpartum ward as this may improve breastfeeding rates. ${ }^{33}$

In conclusion, our findings suggest that despite the rates of low Apgar scores being higher in public patients, the rates of special care nursery admission are lower in 
this group of patients. These findings could not be accounted for by the observed higher rate of caesarean deliveries in private hospitals. It remains to be determined whether these findings are a result of practice differences between public and private hospitals or if clinical differences play a role.

Acknowledgements We thank the Data Linkage Branch of the WA Department of Health and the WA Birth Defects Registry for provision of the data.

Contributors KE initiated the research, designed the study, analysed and interpreted the data, and wrote the article. She will act as guarantor for the paper. SS gave clinical advice and contributed to the writing of the paper. $\mathrm{FAH}, \mathrm{GH}$ and ATL gave advice on the statistical methods used for analysis, discussed ideas and contributed to the paper. DBP, NdeK, HL and FJS supervised the work, gave advice and contributed to the paper. All authors had full access to all of the data in the study and can take responsibility for the integrity of the data and the accuracy of the data analysis.

Funding The research was funded by the Australia's National Health and Medical Research Council (grants 634533 and573 122). The funder had no involvement in the analysis or the writing of the manuscript.

\section{Competing interests None.}

Ethics approval The use of deidentified, administrative health data for this study without patient consent was approved by the Human Research Ethics Committee of the WA Department of Health. This study was performed in accordance with the Declaration of Helsinki.

Provenance and peer review Not commissioned; externally peer reviewed.

Data sharing statement No additional data are available.

\section{REFERENCES}

1. Lipkind HS, Duzyj C, Rosenberg TJ, et al. Disparities in cesarean delivery rates and associated adverse neonatal outcomes in New York City hospitals. Obstet Gynecol 2009;113:1239-47.

2. Robson SJ, Laws P, Sullivan EA. Adverse outcomes of labour in public and private hospitals in Australia: a population-based descriptive study. Med J Aust 2009;190:474-7.

3. Adelson PL, Child AG, Giles WB, et al. Antenatal hospitalisations in New South Wales, 1995-96. Med J Aust 1999;170:211-15.

4. Bai J, Wong FW, Gyaneshwar R, et al. Profile of maternal smokers and their pregnancy outcomes in south western Sydney. $J$ Obstet Gynaecol Res 2000;26:127-32.

5. Kermode M, Fisher J, Jolley D. Health insurance status and mood during pregnancy and following birth: a longitudinal study of multiparous women. Aust N Z J Psychiatry 2000;34:664-70.

6. Dahlen HG, Tracy S, Tracy M, et al. Rates of obstetric intervention among low-risk women giving birth in private and public hospitals in NSW: a population-based descriptive study. BMJ Open 2012;2.

7. Roberts CL, Tracy S, Peat B. Rates for obstetric intervention among private and public patients in Australia: population based descriptive study. BMJ 2000;321:137-41.

8. Hatem M, Sandall J, Devane D, et al. Midwife-led versus other models of care for childbearing women. Cochrane Database Syst Rev 2008;(4):CD004667.

9. Allen VM, O'Connell CM, Liston RM, et al. Maternal morbidity associated with cesarean delivery without labor compared with spontaneous onset of labor at term. Obstet Gynecology 2003;102:477-82.
10. Hansen AK, Wisborg K, Uldbjerg N, et al. Risk of respiratory morbidity in term infants delivered by elective caesarean section: cohort study. BMJ 2008;336:85-7.

11. Tracy SK, Tracy MB, Sullivan E. Admission of term infants to neonatal intensive care: a population-based study. Birth 2007:34:301-7.

12. Austin PC. The relative ability of different propensity score methods to balance measured covariates between treated and untreated subjects in observational studies. Med Decis Making 2009;29:661-77.

13. Heinze G, Juni P. An overview of the objectives of and the approaches to propensity score analyses. Eur Heart $J$ 2011;32:1704-8.

14. Gilbert SA, Grobman WA, Landon MB, et al. Elective repeat cesarean delivery compared with spontaneous trial of labor after a prior cesarean delivery: a propensity score analysis. Am J bstet Gynecol 2012;206:311 e1-9.

15. Musselwhite KL, Faris $\mathrm{P}$, Moore K, et al. Use of epidural anesthesia and the risk of acute postpartum urinary retention. Am J Obstet Gynecol 2007; 196:472 e1-5.

16. Buckmaster AG, Wright IM, Arnolda G, et al. Practice variation in initial management and transfer thresholds for infants with respiratory distress in Australian hospitals. Who should write the guidelines? J Paediatr Child Health 2007;43:469-75.

17. Kowal C, Kuk J, Tamim H. Characteristics of weight gain in pregnancy among Canadian women. Matern Child Health $J$ 2012;16:668-76.

18. Coory MD, Koh GT, Flenady V, et al. Adverse outcomes of labour in public and private hospitals in Australia. Comment. Med J Aust 2009;191:578

19. Zwecker P, Azoulay L, Abenhaim HA. Effect of fear of litigation on obstetric care: a nationwide analysis on obstetric practice. $A m \mathrm{~J}$ Perinatol 2011;28:277-84.

20. Robson SJ, Tan WS, Adeyemi A, et al. Estimating the rate of cesarean section by maternal request: anonymous survey of obstetricians in Australia. Birth 2009;36:208-12.

21. Hopkins K. Are Brazilian women really choosing to deliver by cesarean? Soc Sci Med 2000;51:725-40.

22. Potter JE, Berquo E, Perpetuo IH, et al. Unwanted caesarean sections among public and private patients in Brazil: prospective study. BMJ 2001;323:1155-8.

23. Penn Z, Ghaem-Maghami S. Indications for caesarean section. Best Pract Res Clin Obstet Gynaecol 2001;15:1-15.

24. Einarsdottir K, Kemp A, Haggar FA, et al. Increase in caesarean deliveries after the Australian private health insurance incentive policy reforms. PLOS ONE 2012;7:e41436.

25. Geller EJ, Wu JM, Jannelli ML, et al. Neonatal outcomes associated with planned vaginal versus planned primary cesarean delivery. $J$ Perinatol 2010;30:258-64.

26. Jepson HA, Talashek ML, Tichy AM. The Apgar score: evolution, limitations, and scoring guidelines. Birth 1991;18:83-92.

27. Hashim MJ, Guillet R. Common issues in the care of sick neonates. Am Fam Physician 2002;66:1685-92.

28. King Edward Memorial Hospital Private Patient Incentive: Government of Western Australia, Department of Health.

29. Hey E. Special care nurseries: admitting to a policy. Br Med J (Clin Res Ed) 1983;287:1524-7.

30. Fisher J, Smith A, Astbury J. Private health insurance and a healthy personality: new risk factors for obstetric intervention? J Psychosom Obstet Gynaecol 1995;16:1-9.

31. Davanzo R, Monasta L, Ronfani L, et al. Breastfeeding at NICU Discharge: a multicenter Italian study. J Hum Lact 2012. Published online first 21 July 2012.

32. Fenwick J, Barclay L, Schmied V. Craving closeness: a grounded theory analysis of women's experiences of mothering in the Special Care Nursery. Women Birth 2008;21:71-85.

33. Chi YS, Chee CM, Singh A. Should neonates with specific 'risk factors' be admitted to the special care nursery? Med J Malaysia 1990;45:29-36. 